\title{
Arterialisation of transcutaneous oxygen and carbon dioxide
}

\author{
E BROADHURST, P HELMS, H VYAS, AND G CHERIYAN
}

\author{
Hospital for Sick Children, Institute of Child Health, London
}

\begin{abstract}
SUMMARY We compared previously calculated global correction factors for oxygen and carbon dioxide arterial/transcutaneous ratios with individual in vivo calibrations from the first arterial sample. In infants beyond the neonatal period and older children in vivo calibration confers little benefit over the use of a global calibration correction factor for transcutaneous carbon dioxide, and may reduce the precision with which arterial oxygen can be estimated from transcutaneous oxygen.
\end{abstract}

Transcutaneous oxygen and carbon dioxide provide a convenient, non-invasive method for continuous respiratory monitoring. Transcutaneous oxygen underestimates arterial oxygen because of the skin diffusion barrier to oxygen while transcutaneous carbon dioxide overestimates arterial carbon dioxide because of carbon dioxide production by the skin. These problems may be overcome by allowing for carbon dioxide production by the skin and the oxygen diffusion barrier by using a global correction at calibration.

An alternative approach is to correct transcutaneous readings using arterial blood gas samples. This in vivo calibration assumes that arterial/ transcutaneous relationships remain relatively constant in any one individual. We have previously found in children and infants beyond the neonatal period a mean arterial/transcutaneous oxygen ratio of $1.22^{1}$ and an arterial/transcutaneous carbon dioxide ratio of $0.714 .^{2}$ We therefore compared in vivo calibration with these global correction calibrations in children undergoing intensive care.

\section{Patients and methods}

Data were available from 38 children (17 girls and 21 boys), who had indwelling arterial lines as part of their routine management. Median age was 1.3 (range 0.01 to 11.75 years). Three subjects were neonates all of whom were full term, and all children were haemodynamically stable throughout the study period.

Transcutaneous measurements were made using individual oxygen and carbon dioxide electrodes (Kontron 232 and 230) heated to $44^{\circ} \mathrm{C}$. Oxygen electrodes were calibrated in room air, and carbon dioxide electrodes against $5 \%$ and $10 \%$ carbon dioxide. No corrections were made for varying barometric pressure (assumed to be $101.3 \mathrm{kPa}$ ) or for ambient humidity. The electrodes were applied to the upper anterior chest wall, and 30 minutes were allowed for equilibration.

Arterial blood samples were then taken at hourly intervals for four hours, at times when transcutaneous readings had been stable for at least two minutes. Blood gas measurements were performed using a Radiometer ABL2 blood gas analyser, which was calibrated twice daily with reference solutions and once weekly with tonometered blood.

GLOBAL CORRECTION CALIBRATION

All transcutaneous oxygen values were multiplied by 1.22 (equivalent to calibrating the electrode to read $25.6 \mathrm{kPa}$ in air), ${ }^{1}$ and all transcutaneous carbon dioxide values were multiplied by 0.714 (equivalent to calibrating the electrode to read $7.07 \mathrm{kPa}$ in $10 \%$ carbon dioxide). ${ }^{2}$

\section{IN VIVO CALIBRATION}

At the first hourly blood sample, the arterial/ transcutaneous ratios for oxygen and carbon dioxide were calculated for each patient. These individual ratios were then used as correction factors for all subsequent transcutaneous oxygen and transcutaneous carbon dioxide measurements within each patient.

Global correction and in vivo corrected transcutaneous values were subtracted from subsequent simultaneous arterial values to give the mean errors of prediction of arterial oxygen and arterial carbon dioxide together with their respective confidence intervals. ${ }^{3}$

\section{Results}

(1) OXYGEN MEASUREMENTS

Arterial oxygen ranged from $4.87 \mathrm{kPa}$ to $27.47 \mathrm{kPa}$. One hour after in vivo calibration, the confidence intervals of the prediction error for arterial oxygen were slightly narrower than those found after global correction. At three hours after in vivo calibration (four hours after equilibration) in vivo corrected values were less precise with an increased prediction error (table 1).

Arterial/uncorrected transcutaneous oxygen ratios 
Table 1 Prediction of arterial oxygen

\begin{tabular}{llll}
\hline & $\begin{array}{l}\text { Mean }(S D) \\
\text { error } \\
(k P a)\end{array}$ & $\begin{array}{l}\text { 95\% } \\
\text { Confidence } \\
\text { interval }(k P a)\end{array}$ & $\begin{array}{l}\text { No of } \\
\text { observations }\end{array}$ \\
\hline One hour global & $0.57(1.29)$ & -2.11 to 3.25 & 38 \\
One hour in vivo & $0.55(1.29)$ & -1.93 to 3.03 & 38 \\
Three hour global & $\mathbf{0 . 3 9}(1.85)$ & -3.43 to 4.20 & 28 \\
Three hour in vivo & $\mathbf{0 . 4 9}(2.36)$ & -4.37 to 5.35 & 28 \\
\hline
\end{tabular}

Table 2 Prediction of arterial carbon dioxide

\begin{tabular}{|c|c|c|c|}
\hline & $\begin{array}{l}\text { Mean }(S D) \\
\text { error } \\
(k P a)\end{array}$ & $\begin{array}{l}95 \% \\
\text { Confidence } \\
\text { interval }(k P a)\end{array}$ & $\begin{array}{l}\text { No of } \\
\text { observations }\end{array}$ \\
\hline One hour global & $0.09(0.65)$ & -1.25 to 1.43 & 25 \\
\hline One hour in vivo & $-0.11(0.44)$ & -1.01 to 0.79 & 25 \\
\hline Three hour global & $0.03(0.73)$ & -1.52 to 1.57 & 18 \\
\hline Three hour in vivo & $-0.19(0.63)$ & -1.49 to 1.13 & 18 \\
\hline
\end{tabular}

changed within individuals with time, the mean change from hour one, to hour four was small-1.23 to $1 \cdot 20$ and the respective SDs were $0 \cdot 15$ and $0 \cdot 20$. Arterial/uncorrected transcutaneous ratios had changed by more than $15 \%$ in five out of 38 studies at two hours, in seven out of 38 at three hours, and in 11 out of 28 at four hours. Mean arterial/ uncorrected transcutaneous oxygen and its variability were independent of arterial oxygen.

\section{(2) CARBON DIOXIDE MEASUREMENTS}

The number of observations for carbon dioxide were less than for oxygen (25 compared with 38 ) with 18 data points available at four hours, and arterial carbon dioxide ranged from $2.6 \mathrm{kPa}$ to $11.73 \mathrm{kPa}$. In vivo calibration produced a small improvement in the precision with which arterial carbon dioxide could be estimated (table 2).

Mean arterial/uncorrected transcutaneous carbon dioxide rose from 0.689 at one hour to 0.727 at four hours and the respective SDs rose from 0.062 to $0 \cdot 136$. The proportion of children in whom arterial/ uncorrected transcutaneous carbon dioxide changed by more than $15 \%$ was lower than for oxygen: three out of 25 at two and three hours and four out of 18 at four hours.

\section{Discussion}

In vivo calibration does not appear to confer any clinically important benefit over global correction factors applied at calibration. Indeed, in the case of transcutaneous oxygen, there is a trend towards a reduction in predictive power of arterial oxygen after in vivo calibration (table 1).

Within an individual, arterial/uncorrected transcutaneous oxygen and arterial/uncorrected transcutaneous carbon dioxide change with time and from our data these changes appear to be more pronounced for oxygen than for carbon dioxide. For those children with unstable arterial/transcutaneous ratios, in vivo calibration gives a false sense of security and may result in errors that are unknown and unpredictable. Use of global calibration correction factors derived from the appropriate population results in transcutaneous values in which the errors of estimation of arterial oxygen and carbon dioxide are known. In fullterm infants and older children increasing age does not appear to affect arterial/ transcutaneous relationships for oxygen or carbon dioxide. ${ }^{124}$ In premature infants, however, this is not the case, ${ }^{56}$ and in them it may be more appropriate to use intermittent in vivo calibration.

The confidence interval of $\pm 4-5 \mathrm{kPa} 4.5$ hours after electrode placement for transcutaneous oxygen is large but is certainly narrow enough to detect clinically important changes in oxygenation. These data, however, yet again emphasise the importance of regular arterial sampling to confirm trends displayed on transcutaneous machines.

\section{References}

${ }^{1}$ Vyas H, Helms P, Cheriyan G, Paky F. Transcutaneous oxygen monitoring beyond the neonatal period. Crit Care Med (in press).

2 Cheriyan G, Helms P, Paky F, Marsden D, Chiu MC. Transcutaneous estimation of arterial carbon dioxide in intensive care. Which electrode temperature? Arch Dis Child 1986;61:652-6.

${ }^{3}$ Bland JM, Altman DG. Statistical methods for assessing agreement between two methods of clinical measurement. Lancet 1986;i:730-5.

${ }^{4}$ Marsden D, Chiu MC, Paky F, Helms P. Transcutaneous oxygen and carbon dioxide monitoring in intensive care. Arch Dis Child 1985;60:1158-61.

5 Rome ES, Stork E, Corlo WA, Martin RJ. Limitations of transcutaneous $\mathrm{PO} 2$ and $\mathrm{PCO} 2$ monitoring in infants with bronchopulmonary dysplasia. Pediatrics 1984;74:217-20.

${ }^{6}$ Hamilton PA, Whitehead MD, Reynolds EOR. Underestimation of arterial oxygen tension by transcutaneous electrode with increasing age in infants. Arch Dis Child 1985;60:1162-5.

Correspondence to Dr P Helms, Respiratory Unit, Hospital for Sick Children, Great Ormond Street, London WC1N 3JH.

Accepted 10 May 1988 